\title{
A ELEIÇÃO PRESIDENCIAL DE 2002: a decisão do voto na região da Grande São Paulo
}

\author{
Yan de Souza Carreirão \\ Pedro Alberto Barbetta
}

Este trabalho analisa o comportamento dos eleitores da região da Grande São Paulo, na eleição presidencial de 2002, a partir dos dados de um survey aplicado em 2002 a uma amostra dos eleitores da região. Na primeira seção, tratamos de contextualizar a disputa eleitoral presidencial; em seguida, caracterizamos a base empírica e os aspectos metodológicos da operacionalização da análise; por fim, têm-se a análise propriamente dita e as considerações finais.

\section{Eleição presidencial de 2002: contexto e campanha}

Em 2002, pela primeira vez na história brasileira, foi eleito um presidente claramente vinculado

Artigo recebido em setembro/2003

Aprovado em julho/2004 à esquerda: Lula, com 61\% dos votos válidos, que venceu o candidato Serra no $2^{\circ}$ turno eleitoral. Do contexto em que se deu o processo eleitoral, o fator mais relevante parece ter sido a avaliação que o eleitorado fazia do governo do presidente Fernando Henrique Cardoso (FHC). Havia, de um lado, uma parcela não desprezível que avaliava o governo positivamente (sobretudo por ele ter eliminado a hiperinflação). Por outro lado, na maioria do eleitorado a avaliação era negativa ou neutra ("regular") 1 devido, fundamentalmente, às elevadas taxas de desemprego e à manutenção de enormes desigualdades sociais. Assim, o percentual de eleitores que avaliavam positivamente o governo fornecia combustível para que um candidato situacionista pudesse chegar ao $2^{\circ}$ turno, embora dificilmente pudesse vencê-lo.

Quanto à campanha e aos candidatos, Serra conseguiu formar, junto a uma parcela substancial dos eleitores, a imagem de um administrador ho- 
nesto e competente; seu principal problema era o da credibilidade de suas propostas, na medida em que era o candidato do governo, o qual aos olhos da grande maioria do eleitorado havia deixado a situação social se deteriorar muito.

A análise da evolução das intenções de voto a partir de dezembro de 2001 mostra diversas "ondas" de crescimento de diferentes candidatos, indicando uma grande volatilidade do voto, pelo menos até o final de agosto de 2002 (cerca de quarenta dias antes do $1^{\circ}$ turno). Pode-se dizer, em relação a Roseana Sarney, Garotinho e Ciro Gomes, que seus defeitos, na percepção do eleitorado, limitaram a capacidade de crescimento de suas candidaturas.

Além disso, parece ter sido fundamental para a vitória de Lula uma campanha que tenha conseguido neutralizar dois aspectos centrais da rejeição ao candidato nas eleições anteriores: a idéia de que Lula não tinha preparo para governar e o "radicalismo" seu e do Partido dos Trabalhadores (PT). A sinalização clara de moderação por parte do PT e do candidato contribuiu para reduzir o medo em relação ao segundo aspecto. O trabalho de marketing foi facilitado pelo contexto político: a grande insatisfação com a situação do país reforçava as possibilidades das candidaturas de oposição. Lula era o principal beneficiário em potencial, já que tinha um nome e uma trajetória mais conhecidos, e o PT representava o núcleo duro de oposição a FHC. Quando do início da campanha na TV, o candidato teve a possibilidade de manter uma "postura de estadista", com uma campanha propositiva e com a construção de um estilo que ficou conhecido como "paz e amor", enquanto os demais brigavam entre si na disputa para chegar ao $2^{\circ}$ turno.

\section{Modelo de decisão do voto}

\section{Hipóteses, modelo de análise e variáveis}

Nesta seção serão descritos as hipóteses que nortearam a pesquisa, o tipo de análise estatística e as variáveis utilizadas para formular o esboço de um modelo de decisão de voto entre os eleitores da região da Grande São Paulo. A base empírica em que se sustenta a análise é um survey aplicado a uma amostra de 1.500 eleitores na região em questão, em maio de 2002. ${ }^{2}$

Julgamos relevante testar as hipóteses que direcionaram a pesquisa, não porque tivéssemos a idéia de que todas seriam corroboradas pelos dados, mas por causa do debate em torno delas existente tanto na literatura nacional como na internacional. Na realidade, nossa expectativa inicial a partir de estudo anterior (Carreirão, 2002) - era de que os fatores de maior peso na decisão eleitoral fossem os relacionados às hipóteses 4 e 5 subseqüentes.

1. A hipótese de que as opiniões políticas dos eleitores influenciem sua decisão de voto. Não se trata aqui de propor que os eleitores tenham um "sistema de crença" bastante estruturado (ou seja, têm opiniões "coerentes" entre si). Trata-se apenas de verificar se alguns conjuntos de opiniões relevantes têm associação com o voto, como propõem Almeida e Young (2002). ${ }^{3}$

2. A hipótese de que a "identidade ideológica" dos eleitores (medida por seu autoposicionamento numa escala esquerda-direita) influencie sua decisão de voto. Esta tese é defendida por Singer, que define: "a identificação ideológica passa a ser vista como a adesão a uma posição no contínuo esquerda-direita ou liberal-conservador que, mesmo sendo difusa, isto é, cognitivamente desestruturada, sinaliza uma orientação política geral do eleitor" (Singer, 2000, p. 49). Após calcular coeficientes de correlação entre esta variável e o voto, Singer afirma ter mostrado "que a identificação ideológica havia sido uma poderosa preditora do voto nas eleições [presidenciais] de 1989 e 1994" (Idem, p. 163).

3. A hipótese de que as inclinações ou os "sentimentos" dos eleitores em face dos partidos influenciem seu voto. Na literatura internacional, no que se refere a este tema, há um debate entre a chamada Escola de Michigan e a teoria da "escolha racional", em torno da noção de "identidade partidária". Para a primeira, essa identidade seria forjada em bases afetivas no processo de socialização (antes mesmo da idade adulta), sendo, portanto, mais resistente a mudanças; para a segunda, a identificação partidária seria fruto do resultado da avaliação que o indivíduo faz da experiência acu- 
mulada como eleitor ao longo de sua vida adulta, monitorando as promessas e os desempenhos partidários ao longo do tempo. Nessa perspectiva, a mudança de identificação estaria mais condicionada pelas modificações desse tipo de avaliação. De toda forma, nas duas abordagens a identificação partidária seria um elemento central da decisão do voto, seja como uma escolha baseada numa adesão afetiva, seja pela escolha do partido que apresenta um comportamento mais de acordo com as idéias e/ou interesses do eleitor. Ao longo das últimas décadas do século XX foram sendo apontados sinais do declínio da importância dos partidos políticos, inclusive no que se refere ao peso das identificações partidárias na escolha eleitoral. ${ }^{4}$ Apesar disso, a identificação partidária é ainda um tema central para a literatura sobre o comportamento eleitoral (ver, por exemplo, o excelente estudo de Weisberg e Greene, 2003).

Atualmente no Brasil, embora haja algumas variações, predominam as interpretações que dão pouca relevância à identificação partidária na decisão de voto do eleitor. ${ }^{5}$ De toda forma, os estudos têm trabalhado sistematicamente apenas com a noção de identificação (ou preferência) partidária ("medida", em geral, a partir de uma única pergunta de survey). Uma das propostas do presente trabalho é testar o peso dos sentimentos manifestados pelos eleitores em relação aos partidos, operacionalizando esta variável de forma mais abrangente, a partir de uma bateria maior de questões.

4. A hipótese de que a decisão de voto para presidente seja influenciada pela avaliação que o eleitor faz do desempenho do governo (presidente) em exercício. A tese central em discussão aqui é a de que eleitores que avaliam o desempenho do governo como bom tendem a votar no candidato do governo, e, ao contrário, eleitores que avaliam o desempenho do governo como ruim tendem a votar na oposição. ${ }^{6}$

5. A hipótese de que o voto seja influenciado pela avaliação que os eleitores fazem de características pessoais dos candidatos relevantes para sua capacidade de governar e/ou de cumprir promessas. A partir da década de 1980 tem surgido na literatura internacional um conjunto de análises que não compartilham do diagnóstico, predominante até então, de que o voto influenciado pela avaliação de características pessoais dos candidatos seria necessariamente "irracional", ou "emocional" - em que o julgamento do eleitor seria baseado em critérios superficiais, como a aparência ou o "estilo" do candidato. Fiorina (1981), por exemplo, sustenta que, nas avaliações (feitas pelos eleitores) dos candidatos, os julgamentos retrospectivos (a partir de performances governamentais passadas) ou prospectivos (a partir das propostas para o futuro) e as avaliações centradas em características pessoais relevantes para a habilidade de governar (competência, inteligência etc.) são muito mais importantes do que avaliações baseadas em características físicas e de personalidade, as quais são independentes da habilidade para governar (simpatia, beleza etc.). Rahn et al. (1990), a partir da análise de eleições presidenciais norte-americanas, concluíram que o processo de avaliação das qualidades profissionais e pessoais dos candidatos tem um papel central na decisão final do voto. Segundo esses autores, as avaliações não são nem idiossincráticas nem superficiais; ao contrário, são muito razoáveis, fundadas em processos diários de formação de impressões. Além disso, o contexto político, segundo eles, modifica o processo de avaliação. Os eleitores estruturam suas avaliações das qualidades dos candidatos em termos de liderança política e competência. Esses julgamentos são relacionados com variáveis políticas, como preferência partidária, posições ante issues e ideologia.?

6. A hipótese de que a maioria do eleitorado tenda a votar no candidato que conseguir formar a imagem de defensor dos interesses do "povo" (dos "pobres", dos "trabalhadores", da "maioria"). Essa tese aparece, com certas variações, nos trabalhos de Singer (1990) e Castro (1994).

Com o objetivo de estudar a intenção de voto em função das variáveis relacionadas às hipóteses levantadas (incluindo também algumas variáveis de controle), adotou-se a análise de regressão logística para a intenção de voto em cada um dos quatro principais candidatos. No Apêndice Metodológico 1 são descritas as principais caraterísticas dessa técnica de análise. Foram incluídas no modelo, para cada candidato, as seguintes variáveis independentes: 
a) Variáveis demográficas e socioeconômicas: a1) sexo $[\mathrm{M} / \mathrm{F}$ ]; a2) idade [até 24 anos; 25 a 40 anos; 41 anos ou mais]; a3) renda [até 3 S.M.; + de 3 a 10 S.M.; + de 10 S.M]; a4) escolaridade [escola: até $4^{a}$ série do $1^{\circ} \mathrm{Grau} ; 5^{\circ}$ a $8^{\circ}$ série do $1^{\circ} \mathrm{Grau} ; 2^{\circ} \mathrm{Grau}$; superior]; a5) religião [católica; evangélica; outras/sem religião].

b) Variáveis político-ideológicas: b1) identidade ideológica (ou "posicionamento ideológico") [Esq./Dir.] - autoposicionamento do eleitor numa escala esquerda-direita, com valores de 1 (mais à esquerda) a 7 (mais à direita); ${ }^{8}$ b2) partido político - variável construída (uma para cada candidato: PartLula, PartSerra, PartCiro, PartGaro) com base nas respostas dos entrevistados a três questões, a saber, preferência, simpatia e rejeição aos partidos. A partir das respostas, os entrevistados eram classificados relativamente a cada candidato, em três situações: i) como tendo "sentimentos partidários" que teoricamente desfavoreceriam o voto no candidato; ii) como tendo tendência partidária neutra em relação ao candidato; iii) como tendo sentimentos partidários favoráveis ao voto no candidato (ver Apêndice Metodológico 2); b3) a opinião dos eleitores a respeito do direito de greve para todas as categorias (mesmo polícia e sevidores públicos) [contra; a favor] [DirGreve].

c) Avaliação do governo FHC [AvFHC]: ruim/péssimo; regular; bom/ótimo.

d) Avaliação de atributos dos candidatos: foram consideradas as notas dadas (de zero a dez) pelos entrevistados aos seguintes atributos de cada candidato: d1) honestidade [HonLula, HonSerra, HonCiro, HonGaro]; d2) competência administrativa [CoAdLula, CoAdSerr, CoAdCiro, CoAdGaro]; d3) defesa dos interesses da população [DIPLula, DIPSerra, DIPCiro, DIPGaro].

$A$ análise dos dados

A seguir são mostrados os resultados das análises de regressão logística para cada candidato.

\section{- Lula}

A Tabela 1 mostra as estatísticas para cada variável independente mantida no modelo final (para a intenção de voto em Lula).

Tabela 1

Intenção de Voto em Lula: Estatísticas das Variáveis Mantidas no Modelo

\begin{tabular}{l|c|c|c|c|c}
\hline VARIÁVEL & B & S.E. & WALD & SIGN. & EXP. B \\
\hline DIRGREVE (1) & $-0,505$ & 0,201 & 6,309 & 0,012 & 0,604 \\
PARTLULA & & & 70,758 & 0,000 & \\
PARTLULA (1) & $-1,836$ & 0,249 & 54,189 & 0,000 & 0,160 \\
PARTLULA (2) & $-1,452$ & 0,230 & 39,906 & 0,000 & 0,234 \\
AVFHC & & & 9,490 & 0,009 & \\
AVFHC (1) & 0,831 & 0,280 & 8,826 & 0,003 & 2,297 \\
AVFHC (2) & 0,702 & 0,267 & 6,905 & 0,009 & 2,018 \\
HONLULA (1) & 0,291 & 0,052 & 31,742 & 0,000 & 1,338 \\
COADLULA (1) & 0,272 & 0,052 & 27,621 & 0,000 & 1,312 \\
CONSTANTE & $-3,556$ & 0,417 & 72,872 & 0,000 & 0,029 \\
\hline
\end{tabular}

$\mathrm{N}=$ 944; Chi- quadrado = 599,984; g.l. = 9; Sign. = 0,000; R2 (Nagelkerke $)=0,63$.

$\%$ acerto: outras respostas $=86,5 \%$; Lula $=82,5 \%$; total $=84,9 \%$. 
Restaram no modelo as variáveis "direito de greve”, partido, avaliação do governo FHC, honestidade e competência administrativa. Os dados relativos ao modelo como um todo, mostrados abaixo da tabela (qui-quadrado, significância, $\mathrm{R}^{2} \mathrm{e}$ percentagens de acerto das respostas previstas), indicam que o modelo é bastante satisfatório. Observando a estatística de Wald e a significância, vemos que as variáveis remanescentes são estatisticamente significativas ao nível de 0,01; os coeficientes maiores mostram que a variável "partido" e, em seguida, "honestidade" são as que têm maior peso.

A última coluna da $1^{2}$ linha indica que a chance de votar em Lula por parte de um eleitor que fosse contra o direito de greve (para todas as categorias) era equivalente a apenas cerca de 60\% (Exp $\mathrm{B}=0,604$ ) da de um eleitor que fosse a favor (considerando a probabilidade de votar em Lula ajustada em termos das demais variáveis do modelo. ${ }^{10}$

Quanto à variável partido, a chance de votar em Lula, por parte de um eleitor cujas manifestações em relação a partidos representavam uma situação negativa para o voto no candidato, era cerca de 16\% da chance de um eleitor cujas manifestações representavam uma situação positiva. As chances de um eleitor cujas manifestações em relação a partidos representavam uma situação "neutra" em relação ao voto em Lula eram de cerca de $23 \%$ das de um eleitor cujas manifestações representavam uma situação positiva. ${ }^{11}$

A avaliação de desempenho do governo FHC também mostrou-se relevante: a chance de eleitores que avaliavam o governo como ruim ou péssimo votarem em Lula era cerca de 2,3 vezes a chance de eleitores que avaliavam o governo como ótimo ou bom. E a chance de votar em Lula entre eleitores que avaliavam o governo como regular era o dobro da dos eleitores que avaliavam positivamente.

Quanto aos atributos dos candidatos, como foram operacionalizados como variáveis contínuas, o coeficiente B não é comparável aos das demais variáveis. De toda forma, os coeficientes para honestidade e competência administrativa mostram, como esperado, que as chances de votar em Lula aumentam significativamente quando passamos dos eleitores que davam notas mais baixas para o candidato nestes atributos, para os que davam notas mais altas. Já a variável que indica a avaliação do quanto o candidato defende os "interesses da população", aos olhos dos eleitores, acabou sendo excluída da equação, porque o coeficiente da variável não foi estatisticamente significativo.

Tabela 2

Intenção de Voto em José Serra: Estatísticas das Variáveis Mantidas no Modelo

\begin{tabular}{l|c|c|c|c|c}
\hline VARIÁVEL & B & S.E. & WALD & SIGN. & EXP. B \\
\hline ESCOLA & & & 7,372 & 0,061 & \\
ESCOLA (1) & 1,311 & 0,488 & 7,220 & 0,007 & 3,709 \\
ESCOLA (2) & 1,185 & 0,475 & 6,216 & 0,013 & 3,270 \\
ESCOLA (3) & 1,019 & 0,473 & 4,636 & 0,031 & 2,770 \\
RENDA & & & 6,780 & 0,034 & \\
RENDA (1) & $-0,837$ & 0,362 & 5,353 & 0,021 & 0,433 \\
RENDA (2) & $-0,898$ & 0,348 & 6,666 & 0,010 & 0,407 \\
PARTSERRA & & & 65,654 & 0,000 & \\
PARTSERRA (1) & $-1,910$ & 0,257 & 55,411 & 0,000 & 0,148 \\
PARTSERRA (2) & $-0,357$ & 0,232 & 2,383 & 0,123 & 0,699 \\
AVFHC & & & 13,005 & 0,001 & \\
AVFHC (1) & $-0,948$ & 0,263 & 12,972 & 0,000 & 0,388 \\
AVFHC (2) & $-0,422$ & 0,228 & 3,432 & 0,064 & 0,656 \\
HONSERRA (1) & 0,248 & 0,061 & 16,656 & 0,000 & 1,281 \\
COADSERRA (1) & 0,208 & 0,059 & 12,258 & 0,000 & 1,231 \\
CONSTANTE & $-3,451$ & 0,544 & 40,298 & 0,000 & 0,032 \\
\hline
\end{tabular}

$\mathrm{N}=1005 ;$ Chi- quadrado $=287,988 ;$ g.l. $=11 ;$ Sign. $=0,000 ; \mathrm{R} 2$ (Nagelkerke $)=0,39$.

$\%$ acerto: outras respostas $=94,0 \%$; Serra $=46,4 \%$; total $=84,0 \%$. 


\section{- José Serra}

Restaram no modelo as variáveis escola, renda, competência administrativa, partido, honestidade e avaliação do governo FHC, sendo as últimas três as de maior peso (Tabela 2). O modelo foi menos satisfatório do que o modelo para a intenção de voto em Lula (menores $\mathrm{R}^{2}$ e percentagens de acerto das respostas).

As chances de voto em Serra declinavam com a escolaridade, embora o coeficiente para a variável seja estatisticamente significativo apenas no nível de 0,06; em relação à renda, por outro lado, as chances de Serra eram maiores entre os eleitores de alta renda, comparativamente às duas faixas mais baixas de renda.

A chance de votar em Serra por parte de um eleitor cujas manifestações em relação a partidos representavam uma situação negativa para o voto em Serra era cerca de 15\% da chance de um eleitor cujas manifestações eram positivas.

No que respeita à avaliação de desempenbo do governo FHC, a chance de votar em Serra por parte de um eleitor que avaliava o governo como ótimo ou bom era cerca de 2,5 vezes a de um eleitor que o avaliava como ruim ou péssimo e cerca de $52 \%$ a mais do que a de um eleitor que o avaliava como regular. Quanto aos atributos pessoais do candidato, a situação é semelhante à encontrada para Lula: as chances de votar em Serra aumentam quando passamos dos eleitores que davam notas mais baixas para o candidato nos atributos honestidade e competência administrativa, para os que davam notas mais altas.

\section{- Ciro Gomes}

Permanecem no modelo: posicionamento do eleitor numa escala esquerda-direita, partido, honestidade e competência administrativa (Tabela 3). O modelo é menos satisfatório do que os dos demais candidatos.

A chance de votar em Ciro por parte de um eleitor que se posicionava à esquerda representava cerca de $47 \%$ da de um eleitor que se posicionava à $d i$ reita. Mas a melhor situação para Ciro era entre os eleitores que se posicionavam ao centro (com cerca de $37 \%$ mais chances de votar no candidato, do que os eleitores que se posicionavam à esquerda). ${ }^{12}$

Quanto à variável partido, os coeficientes mostram uma relação com o voto menos consistente do que a encontrada para Lula e Serra. A chance de votar em Ciro, por parte de um eleitor cujas manifestações em relação a partidos representa-

Tabela 3

Intenção de Voto em Ciro Gomes: Estatísticas das Variáveis Mantidas no Modelo

\begin{tabular}{l|c|c|c|c|c}
\hline VARIÁVEL & B & S.E. & WALD & SIGN. & EXP. B \\
\hline ESQDIR & & & 6,245 & 0,044 & \\
ESQDIR (1) & $-0,747$ & 0,448 & 2,780 & 0,095 & 0,474 \\
ESQDIR (2) & $-0,311$ & 0,247 & 1,582 & 0,208 & 1,365 \\
PARTCIRO & & & 13,307 & 0,001 & \\
PARTCIRO (1) & $-0,895$ & 0,570 & 2,467 & 0,116 & 0,408 \\
PARTCIRO (2) & $-0,043$ & 0,569 & 0,006 & 0,940 & 0,958 \\
HONCIRO (1) & 0,316 & 0,075 & 17,576 & 0,000 & 1,371 \\
COADCIRO (1) & 0,250 & 0,074 & 11,463 & 0,001 & 1,283 \\
CONSTANTE & $-5,196$ & 0,721 & 51,941 & 0,000 & 0,006 \\
\hline
\end{tabular}

$\mathrm{N}=950 ;$ Chi- quadrado $=163,892 ;$ g.l. $=8$; Sign. $=0,000 ; \mathrm{R}^{2}($ Nagelkerke $)=0,32$.

$\%$ acerto: outras respostas $=98,5 \% ;$ Ciro $=20,0 \% ;$ total $=89,8 \%$ 
vam uma situação negativa para o candidato, era de cerca de $40 \%$ da de um eleitor cujas manifestações representavam uma situação positiva. Mas a chance de votar em Ciro, por parte de um eleitor cujas manifestações representavam uma situação neutra, era praticamente igual a de um eleitor cujas manifestações representavam uma situação positiva, o que não era esperado teoricamente. $\mathrm{O}$ teste mostra que na comparação entre cada par de categorias não foi possível detectar significância. Um problema em relação a esta variável é o de que pouquíssimos casos foram enquadrados na categoria dos "com influência partidária próCiro", o que gerou uma baixa confiabilidade nas conclusões da análise.

No que diz respeito aos atributos pessoais do candidato, a situação é semelhante à encontrada para Lula e Serra.

\section{- Garotinho}

Permanecem no modelo: escola, honestidade, "defesa dos interesses populares", religião, idade e competência administrativa, sendo as de maior peso estas três últimas (Tabela 4). As estatísticas para o modelo como um todo parecem indicar um modelo razoavelmente satisfatório.

A chance de votar em Garotinho declinava com a idade dos eleitores - entre os mais jovens, era igual a 2,6 vezes a chance entre os eleitores mais velhos. Quanto à variável escolaridade, apesar do coeficiente para a variável (como um todo) ser significativa, os coeficientes para as diferentes categorias de escolaridade não o eram. No que concerne à religião, a força de Garotinho entre os evangélicos é confirmada: o coeficiente de Wald é o maior encontrado no modelo - a chance de votar em Garotinho por parte de um eleitor evangélico representa mais do que o dobro da de um eleitor sem religião (ou de outras religiões, além da católica e das evangélicas) e a diferença de chance de votar em Garotinho é ainda maior se comparamos os evangélicos com os católicos.

Quanto à honestidade e à competência administrativa, a situação é semelhante à encontrada para os demais candidatos. Mas, para Garotinho, a variável "defesa dos interesses da população" também permanece na equação, tendo o mesmo sentido dos outros dois atributos.

Tabela 4

Intenção de Voto em Garotinho: Estatísticas das Variáveis Mantidas no Modelo

\begin{tabular}{l|c|c|c|c|c}
\hline VARIÁVEL & B & S.E. & WALD & SIGN. & EXP. B \\
\hline ESCOLA & & & 8,223 & 0,042 & \\
ESCOLA (1) & 0,449 & 0,462 & 0,946 & 0,331 & 1,567 \\
ESCOLA (2) & $-0,298$ & 0,482 & 0,423 & 0,515 & 0,742 \\
ESCOLA (3) & $-0,004$ & 0,465 & 0,000 & 0,993 & 0,996 \\
IDADE & & & 12,415 & 0,002 & \\
IDADE (1) & 0,956 & 0,396 & 5,842 & 0,016 & 2,602 \\
IDADE (2) & 0,125 & 0,358 & 0,122 & 0,727 & 1,133 \\
RELIGIÃO & & & 22,124 & 0,000 & \\
RELIGIÃO (1) & $-0,303$ & 0,306 & 0,975 & 0,323 & 0,739 \\
RELIGIÃO (2) & 0,828 & 0,328 & 6,371 & 0,012 & 2,288 \\
HONGARO (1) & 0,144 & 0,077 & 3,476 & 0,062 & 1,153 \\
COADGARO (1) & 0,314 & 0,089 & 12,364 & 0,000 & 1,368 \\
DIPGARO (1) & 0,158 & 0,077 & 4,223 & 0,040 & 1,171 \\
CONSTANTE & $-6,482$ & 0,683 & 90,050 & 0,000 & 0,002 \\
\hline
\end{tabular}

$\mathrm{N}=982 ;$ Chi- quadrado $=301,679 ;$ g.l. $=12 ;$ Sign. $=0,000 ; \mathrm{R}^{2}($ Nagelkerke $)=0,44$.

$\%$ acerto: outras respostas $=95,6 \%$; Garotinho $=44,8 \%$; total $=87,1 \%$. 


\section{As variáveis do modelo e o voto}

No conjunto da análise, destacam-se as seguintes conclusões: das variáveis demográficas e socioeconômicas, a escolaridade aparece como relevante para a decisão de voto em Serra e Garotinho. A renda foi relevante apenas para o voto em Serra. Quanto às variáveis idade e religião, foram relevantes para o voto em Garotinho. Fenômeno inédito: pela primeira vez nas eleições presidenciais recentes, a religião dos eleitores foi a variável mais significativa na decisão de voto em um dos candidatos com chance de chegar ao $2^{\circ}$ turno.

No que se refere às variáveis mais estritamente "políticas", uma primeira observação é a de que, num conjunto relativamente grande de opiniões políticas dos eleitores, a única que acabou se mostrando significativa, para um dos candidatos, foi a opinião sobre o direito de greve ("para todas as categorias, inclusive polícia e funcionários públicos"): eleitores com opinião favorável ao direito de greve tinham mais chance de votar em Lula do que eleitores contrários ao direito.
Quanto ao posicionamento dos eleitores numa escala esquerda-direita, acabou por não permanecer significativo em nenhuma das equações finais. Uma possível explicação para isso é a de que não foram testados, em nossos modelos, os efeitos possíveis de interações entre as variáveis. Conforme Carreirão (2002), a associação entre aquele posicionamento e o voto só é forte entre os eleitores com maior escolaridade. Como esta é uma parcela minoritária no conjunto do eleitorado, quando analisamos o impacto da variável no conjunto da amostra, sem introduzir os possíveis efeitos de interação com a variável escolaridade, os efeitos se mostram realmente reduzidos. Como forma de testar, parcialmente, esta hipótese, "rodamos" novamente os mesmos modelos para os quatro candidatos, mas agora considerando apenas os eleitores com $2^{\circ}$ Grau ou nível superior de escolaridade: o resultado é de que apenas no modelo referente a Serra a variável posicionamento esquerda-direita permanece na equação, ao final. Em suma, o conjunto das análises parece indicar um peso relativamente fraco desta variável na decisão de voto dos eleitores de nossa amostra.

Tabela 5

Preferência, Simpatia e Rejeição por Partido (\%)

\begin{tabular}{|c|c|c|c|}
\hline PARTIDO & PREFERÊNCIA & SIMPATIA & REJEIÇÃO \\
\hline $\mathrm{PT}$ & 30,6 & 5,7 & 20,5 \\
\hline PMDB & 6,1 & 3,7 & 5,9 \\
\hline PSDB & 3,7 & 1,5 & 4,3 \\
\hline PFL & 1,7 & 1,2 & 6,5 \\
\hline $\mathrm{PPB}$ & 1,5 & 0,4 & 2,8 \\
\hline PTB & 0,9 & 0,9 & 0,5 \\
\hline PSB & 0,3 & 0,3 & 0,6 \\
\hline PPS & 0,1 & 0,1 & 0,8 \\
\hline $\mathrm{PL}$ & 0,3 & 0,2 & 1,3 \\
\hline PDT & 0,2 & 0,5 & 0,8 \\
\hline PCdoB & 0,1 & - & 0,5 \\
\hline Outros & 0,3 & - & 2,2 \\
\hline SUBTOTAL & 45,8 & 14,5 & 46,7 \\
\hline
\end{tabular}

Fonte: Survey Eleitoral Grande São Paulo, maio/2002. 
A variável "política" que se mostrou mais relevante para o voto em Lula e Serra foi partido. Como esta é uma conclusão que, de certa forma, vai contra grande parte da literatura recente, e como utilizamos uma forma de operacionalizar a variável também diferente da que tem sido tradicionalmente usada, faremos aqui uma discussão mais detalhada dos dados referentes à variável partido.

Uma primeira informação relevante, mostrada na Tabela 5, é relativa à distribuição dos eleitores da amostra segundo suas preferências, simpatias e rejeições em relação aos principais partidos.

O percentual de eleitores que indicavam preferência por algum partido (cerca de 46\%), na amostra da Grande São Paulo, é semelhante aos percentuais que têm sido encontrados em dados recentes para o conjunto do país (ver Carreirão e Kinzo, 2004). Cerca de 14\% dos eleitores manifestavam simpatia e $47 \%$ rejeição por algum partido. Fica também evidente que o PT é o partido central, em torno do qual ocorre a maioria das manifestações de "sentimentos partidários". Seguem-se o PMDB, o PSDB, o PFL e o PPB. Esses cinco partidos concentram cerca de $86 \%$ das manifestações de simpatia e rejeição e 95\% das manifestações de preferência partidária.

Os subtotais dos percentuais de preferência (ou simpatia) e de rejeição não podem ser somados, já que há superposição parcial entre alguns desses tipos de manifestação; de toda forma, apenas $25 \%$ dos entrevistados indicaram não ter preferência, nem simpatia, nem rejeição por algum dos partidos. Ou seja, o conjunto dos eleitores que manifestaram algum "sentimento" em relação aos partidos (75\% da amostra) é bastante superior ao dos que manifestaram preferência (46\%), indicador que tem sido usado nas análises sobre o tema no país.

A Tabela 6 mostra a associação entre os "sentimentos" em relação aos partidos que sustentavam as principais candidaturas e o voto no candidato apoiado por esses partidos.

No que respeita às manifestações em relação ao PT, a seqüência é muito clara: entre os que demonstravam preferência, $77 \%$ pretendiam votar em Lula; esse percentual é de $49 \%$ entre os que manifestavam "simpatia" e cai para apenas 3\% en- tre os que rejeitavam o partido. No que se refere aos outros partidos que formaram a coligação de apoio a Lula, os números são baixos, podendo trazer mais distorções em virtude de pequenos erros amostrais; de toda forma, dos oito eleitores com preferência ou simpatia pelo PL, nenhum pretendia votar em Lula. Já entre os dezenove que manifestavam rejeição ao partido, sete tinham intenção de voto no candidato. O único eleitor que manifestou preferência pelo PCdoB pretendia votar em Lula. Dos oito que manifestaram rejeição, três pretendiam votar em Lula.

Quanto ao PSDB, pode-se dizer que as tendências relativas ao candidato Serra são semelhantes às encontradas entre Lula e o PT: enquanto apenas $2 \%$ dos que rejeitavam o PSDB pretendiam votar em Serra, 54\% dos que manifestavam preferência pelo partido pretendiam votar neste candidato. Tendências semelhantes às do PSDB (embora de menor intensidade) são encontradas em relação ao PMDB (coligado a Serra).

Apenas um eleitor manifestou preferência e um, também, simpatia pelo PPS, ambos com intenção de voto em Ciro Gomes. Dos doze eleitores que manifestavam rejeição ao PPS, nenhum pretendia votar em Ciro. Por outro lado, quanto ao PDT, dos dez que manifestaram preferência ou simpatia, nenhum pretendia votar em Ciro Gomes. Dos doze eleitores que manifestaram rejeição ao partido, um pretendia votar no candidato. Dos 27 entrevistados que manifestaram preferência ou simpatia pelo PTB, cinco pretendiam votar em Ciro, enquanto dos oito que manifestaram rejeição ao partido, dois tinham intenção de votar no candidato.

Quanto a Garotinho, pretendiam votar nele dois dos nove eleitores que manifestavam preferência ou simpatia e seis dos vinte eleitores que manifestavam rejeição ao partido do candidato (PSB), situação oposta à esperada teoricamente.

Apesar de PFL e PPB não terem apoiado oficialmente nenhum partido, as tendências são semelhantes para os dois partidos. Vale a pena destacar o contraste: entre os eleitores com preferência por esses partidos, Lula seria o menos votado dos quatro candidatos, mas seria disparadamente o mais votado entre os que manifestavam rejeição a esses partidos. 
Tabela 6

Voto, Segundo Sentimentos Partidários (\%)

\begin{tabular}{|c|c|c|c|}
\hline Partido & $\begin{array}{l}\text { "Sentimento } \\
\text { partidário" }\end{array}$ & $\begin{array}{c}N^{\circ} \text { de casos } \\
\text { (N) }\end{array}$ & $\begin{array}{l}\text { Intenção de voto no candidato } \\
\text { apoiado pelo partido (\%) }\end{array}$ \\
\hline & Preferência & (459) & 77 \\
\hline \multirow[t]{3}{*}{ PT } & Simpatia & (86) & 49 \\
\hline & Rejeição & (308) & 3 \\
\hline & Preferência & (56) & 54 \\
\hline \multirow[t]{3}{*}{ PSDB } & Simpatia & (23) & 48 \\
\hline & Rejeição & (65) & 2 \\
\hline & Preferência & (1) & 100 \\
\hline \multirow[t]{3}{*}{ PPS } & Simpatia & (1) & 100 \\
\hline & Rejeição & (12) & 0 \\
\hline & Preferência & (4) & 50 \\
\hline \multirow[t]{2}{*}{ PSB } & Simpatia & (5) & 0 \\
\hline & Rejeição & (20) & 33 \\
\hline PL & Preferência & (6) & 17 \\
\hline+ & Simpatia & (3) & 0 \\
\hline \multirow[t]{2}{*}{ PcdoB } & Rejeição & (27) & 37 \\
\hline & Preferência & (92) & 34 \\
\hline \multirow[t]{2}{*}{ PMDB } & Simpatia & (56) & 18 \\
\hline & Rejeição & (88) & 8 \\
\hline PDT & Preferência & (16) & 19 \\
\hline+ & Simpatia & (21) & 10 \\
\hline РTB & Rejeição & (20) & 15 \\
\hline
\end{tabular}

Fonte: Survey Eleitoral Grande São Paulo, maio/2002.

Como se pode ver, há situações bastante diversas, mas, se agruparmos apenas os "sentimentos" manifestados em relação aos partidos a que pertencem os candidatos (PT, PSDB, PPS ou PSB), a associação é muito próxima da esperada teoricamente: três em cada quatro eleitores que manifestaram preferência por um desses partidos pretendiam votar nos candidatos de seus partidos preferidos. A manifestação de simpatia apresenta, como esperado teoricamente, uma associação positiva com o voto, mas de menor intensidade do que aquela apresen- tada entre preferência partidária e voto: $47 \%$ dos eleitores que manifestavam simpatia por um desses partidos pretendiam votar nos seus candidatos. Em contrapartida, apenas $4 \%$ dos eleitores que manifestavam rejeição por um desses partidos votava no candidato deste partido. Considerando os demais partidos que faziam parte das coligações de apoio aos candidatos (PL, PCdoB, PMDB, PDT e PTB), porém, as associações são bem mais fracas.

Por fim, uma análise um pouco mais detalhada (na Tabela 8) em relação a Lula, mostra que a 
Tabela 8

Voto em Lula, Segundo "Sentimentos Partidários" (\%)

\begin{tabular}{l|cccccccccc|c}
\hline \multirow{2}{*}{ VOTO } & \multicolumn{7}{|c|}{ "SENTIMENTOS PARTIDÁRIOS” } & \multirow{2}{*}{ TOTAL } \\
\cline { 2 - 12 } & 1 & 2 & 3 & 4 & 5 & 6 & 7 & 8 & 9 & 10 & \\
\hline LULA & 85 & 74 & 61 & 46 & 32 & 23 & 21 & 30 & 3 & 2 & 38 \\
OUTROS & 11 & 23 & 39 & 39 & 52 & 49 & 64 & 63 & 79 & 86 & 48 \\
B/N/NS/NR & 4 & 3 & 0 & 15 & 16 & 28 & 15 & 7 & 18 & 12 & 14 \\
\hline TOTAL (N) & 113 & 346 & 18 & 68 & 44 & 433 & 33 & 137 & 196 & 112 & 1500 \\
\hline
\end{tabular}

1 = Pref. pelo PT e Rej. por partido de (ou coligado a) cand. Adversário; 2 = Pref. pelo PT, sem Rej. por partido de (ou coligado a) cand. Adversário; 3 = Simp. pelo PT e Rej. por partido de (ou coligado a) cand. Adversário; $4=$ Simp. pelo PT, sem Rej. por partido de (ou coligado a) cand. Adversário; 5 = [Pref. ou Simp. por PCdoB ou PL, sem Rej. pelo PT] + [Sem Pref. ou Simp. Part. e Rej. por partido de (ou coligado a) cand. adversário]; 6 = Sem Pref. ou Simp. Part. e sem Rej. (por partidos que sustentavam candidatos na disputa); 7 = [Sem Pref. ou Simp. (por partidos na disputa) e Rej. por PCdoB ou PL] + [Pref. ou Simp. por partido de (ou coligado a) cand. adversário e Rej. por (outro) partido de candidato adversário]; 8 = Pref. ou Simp. por partido de (ou coligado a) cand. adversário e sem Rej. ou Rej. por PCdoB ou PL; 9 = Rej. pelo PT, sem Pref. ou Simp. por partido de (ou coligado a) cand. Adversário; 10 = Rej. pelo PT, com Pref. ou Simp. por partido de (ou coligado a) cand. adversário.

Fonte: Survey Eleitoral Grande São Paulo, maio/2002.

influência dos diferentes "sentimentos partidários" manifestados pelos eleitores, sobre sua decisão de voto, parece seguir uma escala contínua. Tais "sentimentos" foram agrupados em dez categorias, seguindo uma escala que vai das situações teoricamente mais favoráveis às mais desfavoráveis ao voto em Lula. ${ }^{13}$

A análise da associação entre os "sentimentos partidários" dos eleitores e suas intenções de voto mostra que, com uma única exceção, há um declínio monotônico da intenção de voto em Lula, à medida que se passa das situações teoricamente mais favoráveis para as mais desfavoráveis ao voto no candidato.

Deve-se ainda acrescentar que, ao "rodar" o mesmo modelo de regressão logística - tendo a intenção de voto em Lula como a variável dependente, mas utilizando a variável "partido" como uma variável contínua (com os dez pontos acima), no lugar da variável categórica (com três posições, como definido anteriormente) -, não há modificação significativa no modelo.
Isso torna mais robusta a conclusão de que, pelo menos para o candidato vencedor, a variável partido foi realmente relevante na decisão de voto, o que minimiza uma possível suspeita de que essa conclusão seria fruto de artefato metodológico, ou seja, da forma como a variável foi operacionalizada.

De toda forma, é necessário destacar que a influência dessa variável se deve em grande parte ao peso dos sentimentos manifestados em relação ao PT. Para Serra, Garotinho e Ciro, os percentuais de intenção de voto superam os percentuais de manifestações de preferência ou simpatia pelos partidos que os apoiavam. A rejeição ao PT, manifestada por parcela desses eleitores, pode explicar por que eles não votavam em Lula, mas não por que escolhiam especificamente um desses três candidatos.

Passando agora a analisar outra variável, a avaliação feita pelos eleitores do desempenbo do governo em exercício aparece como relevante para os votos em Lula e Serra: conforme o esperado, quan- 
to pior a avaliação do governo, maior a chance de votar em Lula e menor a de votar em Serra.

Uma questão importante é saber se essa avaliação do governo é influenciada pelas opiniões políticas dos eleitores. Testamos, então, um modelo em que a avaliação de governo passou a ser a variável dependente, sendo que todas as variáveis "políticas" do modelo inicial permaneceram como variáveis independentes. ${ }^{14}$ Obtivemos um modelo com as seguintes características: $\mathrm{R}^{2}$ (Nagelkerke $)=0,11 ; \%$ de acerto: avaliação negativa $=$ $82,9 \%$; avaliação positiva $=40,4 \%$; total $=65,9 \%$. As variáveis que permaneceram no modelo foram as opiniões relacionadas com o direito de greve, com o pagamento (ou não) da dívida externa, com um índice de estatismo e a variável PartSerra (partido, em relação a Serra), sendo as duas últimas as de maiores coeficientes de Wald. Os coeficientes mostram que as associações seguiram o sentido esperado: crescimento da avaliação do governo, entre os eleitores contrários ao direito de greve para todas as categorias; entre os que discordavam totalmente da idéia de não pagar a dívida externa; entre os menos estatistas e entre os que manifestavam "sentimentos partidários" que teoricamente influenciariam positivamente $\mathrm{o}$ voto em Serra. Os dados revelam, portanto, que parte dessa avaliação era "explicada" por tais posicionamentos. De toda forma, dado que o modelo não é muito satisfatório, há uma parcela da avaliação feita pelos eleitores do desempenho do governo FHC que parece independente dos seus posicionamentos políticos e partidários, devendo ser feita a partir de critérios de outra natureza.

Por fim, variáveis que se mostraram das mais relevantes foram alguns dos atributos pessoais dos candidatos (segundo a avaliação dos eleitores), especialmente honestidade e competência administrativa: para todos os candidatos, como esperado, a chance de voto aumentava consideravelmente à medida que se passava dos eleitores que avaliavam mal o candidato, para os que o avaliavam bem. No que se refere ao atributo "defesa dos interesses populares", só se mostrou relevante para o voto em Garotinho.

Quanto aos atributos pessoais dos candidatos, temos que lidar com um problema que tende a ser bem menor no que se refere às demais variáveis. Trata-se de uma tendência à "racionalização" que os entrevistados podem ter ao responder questões sobre os candidatos em que pretendem votar. Há uma tendência a avaliar positivamente os atributos do candidato escolhido, mesmo que a escolha tenha se dado por outros motivos. ${ }^{15}$

Para minimizar esse problema, operacionalizou-se novamente as variáveis relativas aos atributos por intermédio de um diferencial entre os candidatos, a partir das notas dadas a cada um deles, em cada atributo. Com isso, um entrevistado só foi considerado como manifestando uma tendência pró-Lula (por exemplo) em determinado atributo se a nota dada a Lula neste atributo fosse maior do que a de todos os demais candidatos. Embora essa forma de operacionalizar as variáveis relativas aos atributos dos candidatos não esteja isenta do problema mencionado (e talvez nenhuma outra esteja), acreditamos que ela possa amenizá-lo, comparativamente à utilização das notas. No caso do diferencial, há uma possibilidade de o eleitor que decidiu votar em Lula por outro motivo, mesmo apontando uma nota alta para ele, indicar nota de igual valor a pelo menos um dos outros candidatos no atributo em questão. O resultado, porém, é o de que com essa operacionalização os coeficientes para essas variáveis se tornam muito elevados (para praticamente todos os atributos, para os quatro candidatos), indicando que o eleitor que atribui um diferencial para um candidato num determinado quesito têm uma chance muito maior de votar neste candidato do que um eleitor que não atribui um diferencial para o candidato. Contudo, apenas uma proporção relativamente pequena de eleitores ( $4 \%$ a $24 \%$, conforme o candidato e o atributo; média de $14 \%$ no conjunto) acaba por apontar diferenciais para um candidato, contrastada a uma alta proporção que não o faz.

Em suma, os resultados da análise sobre o "peso" dessas avaliações na decisão de voto não são conclusivos: a forte associação que parece haver entre a avaliação que os eleitores fazem de atributos dos candidatos e seu voto pode derivar, em parte, de um processo de "racionalização" por 
parte dos eleitores. A tentativa metodológica de reduzir esse problema levou-nos a encontrar uma associação ainda mais forte entre as variáveis, mas apenas para uma pequena parcela da amostra, reduzindo, assim, o possível peso dos atributos dos candidatos no resultado agregado da eleição.

Tínhamos uma hipótese complementar, de que parte da avaliação dos atributos pessoais dos candidatos feita pelos eleitores poderia também ser "explicada" pelas variáveis de natureza mais propriamente política. Fizemos, então, uma análise complementar para testar parcialmente essa hipótese. Formulando um modelo em que a variável dependente era a "honestidade de Lula" (operacionalizada como variável binária: $0=$ diferencial negativo ou nulo; 1 = diferencial positivo) e tendo como variáveis independentes as variáveis "políticas" do modelo inicial (mais a avaliação do governo), obtivemos um modelo com poder preditivo não muito alto: embora significativo ao nível de 0,01 , o $\mathrm{R}^{2}$ (Nagelkerke) é de 0,21, com os seguintes percentuais de acerto: diferencial negativo $/$ nulo $=$ $100 \%$; diferencial positivo $=0 \%$; total $=76,9 \% \cdot{ }^{16}$

Assim, realmente uma parte das avaliações feitas pelos eleitores a respeito das qualidades pessoais dos candidatos parece poder ser "explicada" pelas opiniões e posicionamentos políticos dos eleitores. De outro lado, porém, boa parte dessa avaliação parece ser feita a partir de considerações menos "contaminadas" por posicionamentos políticos prévios.

\section{Considerações Finais}

Nossa análise comprova o quão complexa é a decisão de voto dos eleitores da Grande São Paulo: algumas variáveis (especialmente as demográficas e socioeconômicas) mostraram-se relevantes para "explicar" o voto em um candidato, mas não para os demais. As variáveis que se mostraram mais freqüentes e com peso mais considerável foram partido, honestidade, competência administrativa (do candidato) e avaliação de desempenho do governo em exercício.

Quanto à avaliação feita pelos eleitores dos atributos dos candidatos, cabe lembrar as ressal- vas feitas na análise a respeito dos possíveis efeitos de uma "racionalização" por parte dos entrevistados em suas respostas ao survey. Acreditamos, de toda forma, que seja necessário um maior debate sobre a possível influência desse tipo de variável na decisão de voto em todo o país.

Especialmente relevante foi o peso que a variável "partido" adquiriu na análise. Acreditamos que os resultados apresentados possam contribuir para um debate metodológico a respeito da forma pela qual deva ser tratada esta variável. A análise confirmou a expectativa teórica de que uma manifestação de "simpatia" (tal como aqui definida) a um partido está também associada a uma tendência de voto no candidato do partido, embora de forma mais fraca do que no caso de uma manifestação de "preferência". Isso pode indicar a necessidade de se reconsiderar a maneira de medir sentimentos "positivos" em relação a partidos (e sua influência sobre o voto). Contudo, especialmente a rejeição a partidos parece ter influência significativa na decisão de voto, restringindo o campo das opções palatáveis a uma parcela considerável do eleitorado. Mesmo levando em conta as limitações relativas à extrapolação das conclusões a que chegamos, importa destacar que a influência dos "sentimentos partidários" no resultado agregado da eleição é superior àquela que teria sido estimada a partir da consideração apenas das manifestações de preferência partidária dos eleitores. Se nossa análise estiver correta, uma avaliação adequada da possível influência dos "sentimentos partidários" dos eleitores sobre sua decisão de voto precisa incorporar não só suas preferências partidárias, como tem sido feito na quase totalidade dos estudos no país, mas também outras manifestações dos eleitores.

É importante apontar alguns dos limites deste trabalho no que se refere à "validade externa" de suas conclusões. O universo aqui estudado - eleitores da região da Grande São Paulo - impede a extrapolação das conclusões para o comportamento do conjunto do eleitorado nacional. Particularmente importante é o fato de que a porcentagem de eleitores com preferência pelo PT $(30,6 \%)$ é, na amostra, bem superior às proporções encontradas no âmbito nacional (em torno 
de 21\%, no mês em que foi aplicado o survey). Isso certamente contribuiu para que o "peso" da variável partido fosse tão importante. Deve-se considerar, ainda, que foi analisada apenas a eleição presidencial, em que a associação PT-Lula era muito nítida. Para outros níveis eleitorais, acreditamos que a associação entre os "sentimentos partidários" dos eleitores e seu voto seja menos intensa. Um outro fator que pode ter contribuído para "inflacionar" o peso da variável partido é o fato de que o survey no qual se apóia a análise foi realizado em maio de 2002, antes, portanto do início do Horário de Propaganda Eleitoral. Como é a partir daí que a campanha ganha força e a ênfase nos candidatos se intensifica, talvez com um survey mais próximo do momento da eleição se chegasse à conclusão de que a variável "partidos" influenciasse menos a decisão de voto. ${ }^{17}$

De toda forma, acreditamos que a análise realizada possa estimular o debate metodológico a respeito das formas de operacionalização das variáveis e, além disso, possa nos dar pistas de como operam diversas variáveis relevantes na decisão de voto de um subconjunto relevante do eleitorado nacional.

\section{Apêndice metodológico 1: a análise de regressão logística}

Para cada candidato, a variável dependente intenção de voto - foi definida como 0 e 1 (um, quando a intenção de voto é no candidato em questão; zero, para qualquer outra situação). Sejam $\mathrm{P}\{\mathrm{Y}=1\}$, a probabilidade de intenção de voto no candidato, e $\mathrm{X}_{1}, \mathrm{X}_{2}, \ldots$, as variáveis independentes. Pelo modelo de regressão logística, a probabilidade de intenção de voto no candidato, $\mathrm{P}\{\mathrm{Y}$ $=1\}$, pode ser predita por

$$
\mathrm{P}\{\mathrm{Y}=1\}=\frac{\exp \left\{\boldsymbol{\beta}_{0}+\boldsymbol{\beta}_{1} \mathrm{X}_{1}+\boldsymbol{\beta}_{2} \mathrm{X}_{2}+\ldots\right\}}{1-\exp \left\{\boldsymbol{\beta}_{0}+\boldsymbol{\beta}_{1} \mathrm{X}_{1}+\boldsymbol{\beta}_{2} \mathrm{X}_{2}+\ldots\right\}}
$$

onde $\beta_{0}, \beta_{1}, \beta_{2}, \ldots$ são parâmetros que podem ser estimados a partir da amostra.
No presente trabalho, com exceção dos atributos dos candidatos, as variáveis independentes $\mathrm{X}_{1}$, $\mathrm{X}_{2}, \ldots$ são todas categóricas. Para as variáveis originalmente dicotômicas, como sexo, a codificação é direta ( 0 , para uma categoria, e 1, para a outra). Para as variáveis politômicas, como escola, foi usada uma variável indicadora para cada categoria (1, quando o elemento pertence à categoria; 0 , caso contrário), com excessão da categoria do nível mais alto, adotada como base de comparação.

Os coeficientes $\beta_{0}, \beta_{1}, \beta_{2}, \ldots$ das variáveis independentes, após estimados a partir dos dados pelo princípio da máxima verossimilhança, fornecem informações sobre a influência de cada variável sobre a intenção de voto. Quanto maior o coeficiente, maior é a influência. O sinal do coeficiente informa o sentido da relação de causalidade. Na apresentação dos resultados, optamos por analisar o valor da função exponencial aplicada a cada coeficiente, que representa a razão da chance de intenção de voto ao candidato, entre indivíduos da categoria em pauta e indivíduos da categoria do nível mais alto da variável em estudo, "descontando" o efeito das outras variáveis do modelo.

As estatísticas e os testes para a avaliação do modelo são construídos a partir da função de verossililhança, L, que é uma medida de quão verossímil é o modelo proposto em relação aos dados efetivamente observados. Sendo $\mathrm{L}_{0}$ a função de verossimilhança num modelo sem variáveis independentes (apenas com o termo constante $\beta_{0}$ ) e $L_{p}$, a função de verossimilhança num modelo com as $p$ variáveis independentes, a estatística

$$
G=-2 \log \left(\frac{L_{0}}{L_{p}}\right)
$$

- que tem, para amostras grandes, distribuição qui-quadrado com $p$ graus de liberdade - pode ser usada para testar a significância do modelo como um todo. Ou seja, quando o valor- $p$, baseado no resultado da estatística $G$ e na distribuição quiquadrado $\operatorname{com} p$ graus de liberdade, for menor que o nível de significância adotado, então as $p$ variáveis, em conjunto, têm influência significativa na probabilidade do eleitor votar no candidato. 
$\mathrm{Na}$ regressão linear, é comum apresentar o coeficiente de determinação $\mathrm{R}^{2}$, cujo valor está no intervalo entre 0 e 1 , como representando a proporção da variância da variável dependente, que pode ser "explicada" pelas variáveis independentes, segundo o modelo adotado. Na regressão logística, não existe um coeficiente com esta interpretação, mas existem propostas de generalizações do coeficiente $\mathrm{R}^{2}$, em que quanto maior o seu valor, maior é o poder preditivo do modelo com os dados da amostra. No caso do $\mathrm{R}^{2}$ proposto por $\mathrm{Na}-$ gelkerke, o resultado estará sempre no intervalo de 0 a $1 .{ }^{18}$ Em termos dos dados da amostra, $\mathrm{R}^{2}=0$ indica que o modelo não colabora em nada para predizer a intenção de votos, e $\mathrm{R}^{2}=1$ indica que $\mathrm{O}$ modelo prediz corretamente todas as intenções de voto da amostra. Cabe observar que, num contexto geral, o poder preditivo do $\mathrm{R}^{2}$ é superavaliado, pois se deseja um modelo que prediga adequadamente a intenção de votos de indivíduos em geral, e não especificamente dos indivíduos cujo resultado é conhecido e que foram usados na própria construção do modelo.

Outra maneira de avaliar a qualidade do modelo é por meio de sua capacidade em predizer a intenção de voto do candidato. Usando a equação de $\mathrm{P}\{\mathrm{Y}=1\}$, com os parâmetros $\mathrm{b}_{0}, \mathrm{~b}_{1}, \mathrm{~b}_{2}, \ldots$ estimados a partir da amostra, podemos predizer a probabilidade de cada elemento da amostra votar no candidato em questão. Se for considerado $\mathrm{P}\{\mathrm{Y}$ $=1\}>0,5$ (ponto de corte) como uma predição favorável ao candidato, pode-se avaliar a proporção de casos em que a predição do modelo coincidiu com a intenção de voto do eleitor (\% acerto). O mesmo problema de superavaliação do poder preditivo apontado acima ocorre aqui.

A seleção das variáveis independentes pode ser feita a partir de algoritmos automatizados. Neste trabalho foi usado o algoritmo Backward $L R$, que inicia o processo com um modelo incluindo todas as variáveis. As variáveis não significativas vão sendo excluídas uma de cada vez, até resultar num conjunto de variáveis em que todas são significativas ao nível de significância estabelecido. Neste algoritmo, a significância é verificada por meio de testes da razão de máxima-verossimilhança, em que a estatística G compara o modelo com e sem a variável em questão, ou seja,

$$
G=-2 \log \left(\frac{L_{q}-1}{L_{p}}\right)
$$

onde Lq é a função de verossimilhança no modelo com $q$ variáveis e Lq-1 é a função de verossimilhança sem a variável que está sendo testada. O valor - $p$ é obtido por meio da distribuição quiquadrado com 1 grau de liberdade.

\section{Apêndice metodológico 2: operacionalização da variável "partido"}

A variável "partido" (uma para cada candidato) foi construída a partir das respostas às questões sobre preferência ["Qual é o partido político de sua preferência ?" (espontânea e única)]; simpatia [(Só para quem não indicou preferência por algum partido) "Mesmo não tendo preferência por nenhum partido, o(a) sr(a). tem simpatia ou inclinação por um destes partidos ?" (mostrar cartão com lista de partidos)] e rejeição ["Qual o partido em que o(a) sr(a). não votaria nos candidatos de jeito nenhum ?" (espontânea e única)] partidárias. Embora a diferença de significados entre preferência e simpatia não seja clara, a simpatia será tomada aqui como uma manifestação positiva em relação a um partido, mas de menor intensidade do que a preferência, dados os enunciados das questões.

Passos para a construção da variável partido, na forma como foi utilizada:

$1^{\circ}$ ) Recodificação das variáveis: para preferência, simpatia e rejeição, para cada candidato, foi feita uma recodificação da seguinte forma:

0 = sem preferência (simpatia ou rejeição) ou preferência (simpatia ou rejeição) por partido que não tenha lançado candidato, nem esteja coligado a um. $1=\mathrm{PC}=$ partido do candidato (em que o entrevistado pretendia votar).

$2=$ PCC $=$ partido coligado ao do candidato $(\mathrm{em}$ que o entrevistado pretendia votar).

$3=\mathrm{PCA}=$ partido de candidato adversário (do candidato que o entrevist. pretendia votar). 
$4=$ PCCA $=$ partido coligado ao candidato adversário (do candidato que o entrevistado pretendia votar).

$2^{\circ}$ ) Criação da variável Partido = Preferência + Simpatia+Rejeição (para cada candidato), resultando em diversas combinações, que foram depois agregadas em seis tipos diferentes (indicadas pelas letras de A a F abaixo), cada um correspondendo a um valor da variável Partido (1, quando a combinação de preferência, simpatia e rejeição manifestadas pelo entrevistado representar, do ponto de vista teórico, uma tendência favorável ao voto no candidato em questão; $O$, quando esta combinação for neutra em relação a escolha do candidato; -1, quando a combinação representar uma tendência negativa de voto no candidato em questão).

A) Pref. ou simp. por PC ou PCC, sem rejeição a $\mathrm{PC}$ ou $\mathrm{PCC}=1$.

B) Pref. ou simp. por PC, rejeição a PCC $=1$.

C) Sem pref. ou simpatia (ou pref. ou simpatia por partido sem candidato e sem coligação com candidato) e sem rejeição a PC ou PCC $=0$.

D) Pref. ou simp. por PCC, rejeição a $\mathrm{PC}=-1$.

E) Sem pref. ou simpatia (ou pref. ou simpatia por partido sem candidato e sem coligação com candidato), com rejeição a PC ou PCC $=-1$.

F) Pref. ou simp. por PCA ou PCCA (independente de rejeição) $=-1$.

Obs.: Alguns dos critérios usados para atribuir os valores das combinações foram:

1) Preferência, simpatia ou rejeição a PPB e PFL (além de "outros partidos"), foram considerados com valor zero, ou seja, não influenciando na escolha de candidatos.

2) Preferência ou simpatia por PC > rejeição por PCC.

3) Rejeição por PC > preferência ou simpatia por PCC.

4) Rejeição por PCA ou PCCA não implica necessariamente tendência favorável ao candidato em questão, podendo redundar em voto para um $3^{\circ}$ candidato.
5) Preferência ou simpatia por PCA ou PCCA representa tendência negativa para o voto no candidato em questão.

\section{NOTAS}

1 Os eleitores que avaliavam o governo FHC como "regular" somavam $40 \%$ antes do $1^{\circ}$ turno. De 1989 para cá, com exceção do período pré-eleitoral de 1994, a grande maioria dos eleitores que avaliam o governo como regular tende a votar contra o governo.

2 Survey aplicado no âmbito da pesquisa Partidos e Representação Política: O Impacto dos Partidos na Estruturação da Escolha Eleitoral no Brasil, coordenada pela profa. Dra. Maria D’Alva Gil Kinzo (Depto. de Ciência Política da USP) e financiada pela Fapesp.

3 Converse (1964) elaborou a noção de "sistema de crenças", constatando que a maioria do eleitorado não tem um sistema estruturado. Para uma revisão de aspectos importantes do debate sobre esse tema na literatura norte-americana, ver Singer (2000), Rennó (2001) e Carreirão (2002).

4 Boas revisões da literatura internacional sobre identificação partidária podem ser encontradas em Dalton e Wattenberg (1993) e Weisberg e Greene (2003). Sobre o declínio do papel dos partidos políticos, ver Wattenberg $(1991,1998)$ e Dalton e Wattenberg (2000), entre outros.

5 Carreirão e Kinzo (2004) fazem uma revisão da literatura sobre o tema, no que se refere ao atual sistema partidário brasileiro.

6 Além da vasta literatura internacional (Key, 1966; Fiorina, 1981; Lewis-Beck, 1988), esta tese aparece, de alguma forma, em muitos textos recentes no Brasil: Lavareda (1989); Muszynski e Mendes (1990); Albuquerque (1992); Figueiredo (1994); Mendes e Venturi (1994); Meneguello (1995); Kinzo (1992); Carreirão (1999, 2002), entre outros.

7 Para outros estudos que valorizam a avaliação de atributos dos candidatos na decisão de voto dos eleitores, ver Miller et al. (1986) e Popkin (1994).

8 As posições na escala foram recodificadas da seguinte forma (seguindo Singer, 2000, e Carreirão, 2002): 1 e 2 = esquerda; 3 a 5 = centro; 6 e 7 = direita. 
9 Outras opiniões políticas foram incluídas originalmente num modelo mais completo. Como nenhuma delas permanecia nas equações finais, foram eliminadas e passamos a trabalhar apenas com as variáveis descritas acima, o que reduz o número de casos perdidos por não resposta.

10 Se todas as variáveis independentes fossem não correlacionadas e as observações (amostra) fossem feitas uniformemente em relação às combinações entre elas - como pode ser feito em estudos experimentais -, poderíamos ter medidas independentes do efeito de cada variável. Como isso não acontece, o efeito de cada variável pode ser influenciado pelas demais variáveis. A análise simula manter constantes as demais variáveis, para tentar medir apenas o efeito da variável em questão. Para as demais conclusões, ao longo do texto, tiradas a partir da interpretação dos Exp (B), também deve ser levada em conta essa consideração.

11 Para uma compreensão adequada das interpretações feitas aqui, é importante ter em conta que a ordenação das categorias, em cada variável, é aquela descrita no item "Hipóteses, modelo de análise e variáveis".

12 As conclusões a respeito desta variável devem ser vistas com ressalva, dado que as significâncias dos coeficientes correspondentes às categorias que a variável assume estão acima do que se considera aceitável $(0,05)$.

13 Embora se possa discordar da posição específica de alguma(s) das manifestações em relação aos partidos, na ordenação por nós proposta, acreditamos que essa ordenação reflete de forma razoavelmente adequada as expectativas teóricas que possam vincular essas manifestações dos eleitores com seu voto. A preferência ou a simpatia por PCdoB ou PL, sem rejeição pelo PT, foi incluída junto com a categoria "sem preferência ou simpatia partidária e rejeição por partido de candidato adversário", porque tinha apenas seis casos e achamos que se aproximaria desta última categoria mais do que da categoria anterior.

14 De forma a podermos realizar esse teste utilizando a regressão logística, recodificamos a variável "avaliação de governo" para apenas duas categorias: 0 = péssimo/ruim/regular "pra pior"; 1 = regular "pra melhor"/bom/ótimo.
15 Como, em geral, grande parte dos entrevistados não quer ser vista como incoerente, tende a racionalizar respostas. $\mathrm{O}$ caso mais grave parece ser o relativo às avaliações diretas de atributos dos candidatos. Comparativamente, parece mais fácil, para um eleitor mediano, "perceber" que está "sendo incoerente", se ele diz que vai votar em Lula e, simultaneamente, diz que o mais honesto é Serra, do que se ele indica preferência por um partido e vota no candidato de outro partido (ou se diz estar no ponto 2 da escala esquerda-direita e vota no candidato que julgamos mais à direita do espectro ideológico, ou se indica uma tendência de apoio a uma menor intervenção do Estado na economia e vota em Lula).

16 Incluir as variáveis demográficas, além das "políticas", não melhora significativamente o modelo. Modelos semelhantes para os outros atributos de Lula fornecem resultados semelhantes.

17 Devemos algumas dessas observações aos comentários de Maria D’Alva Kinzo, Antônio Lavareda e Orjan Olsen.

18 A respeito do uso do R2 de Nagelkerke, ver o site: http://linuxndsweb.mcs.muohio.edu/doc/sassystem/SUGI25/25/st/25p256.pdf.

\section{BIBLIOGRAFIA}

ALBUQUERQUE, José A. Guilhon. (1992), "Identidade, oposição e pragmatismo: uma teoria política do voto". Lua Nova, 26:53-79.

ALMEIDA, Alberto C. \& YOUNG, Clifford. (2002), "As bases ideológicas do comportamento eleitoral". Rio de Janeiro (mimeo.).

BALBACHEVSKY, Elizabeth. (1992). "Identidade partidária e instituições políticas no Brasil". Lua Nova, 26: 133-165.

BAQUERO, Marcello. (1996), "A tese da mobilização cognitiva e o declínio dos partidos". Trabalho apresentado no XX Encontro Anual da Anpocs, Caxambu.

CAMPBELL, Angus et al. (1960), The American voter. Nova York, Wiley.

CARREIRÃO, Yan. (1999), "Avaliação do governo e 'voto econômico'”. Lua Nova, 48: 213-232. 
(2002), A decisão de voto nas eleições presidenciais brasileiras. Rio de Janeiro/Florianópolis, Editora da FGV/EDUFSC.

CARREIRÃO, Yan \& KINZO, Maria D'Alva G. (2004), "Partidos políticos, preferência partidária e decisão eleitoral no Brasil (1989-2002)". Dados, 47 (1):131-167.

CASTRO, Mônica M. M. (1994), Determinantes do comportamento eleitoral: a centralidade da sofisticação política. Tese de doutorado, Rio de Janeiro, Iuperj (mimeo.).

CLARKE, Harold \& STEWART, Marianne. (1998), "The decline of parties in the minds of citizens". Annual Review of Political Science, 1: 357-378.

CONVERSE, Phillip. (1964), "The nature of belief systems in mass publics", in D. Apter (ed.), Ideology and discontent, Nova York, Free Press.

DALTON, Russell J. \& WATTENBERG, Martin. (1993), "The not so simple act of voting", in A. Finifter (ed.), State of political science II, Washington, American Political Science Association.

DALTON, Russell J. \& WATTENBERG, Martin (eds.). (2000), Parties without partisans: political changes in advanced industrial democracies. Oxford, Oxford University Press.

DOWNS, Anthony. (1957), An economic theory of democracy. Nova York, Harper \& Row Publishers.

FIGUEIREDO, Rubens. (1994), "Opinião pública, intencionalidade e voto". Opinião Pública, II (2): 73-82.

FIORINA, Morris. (1981), Retrospective voting in American national elections. New Haven, Yale University Press.

KEY, V. O. (1966), The responsible electorate: rationality in presidential voting, 19361966. Cambridge, Belknap Press.

KINZO, M. D’Alva. (1992), “A eleição presidencial de 1989: o comportamento eleitoral em uma cidade brasileira”. Dados, 35 (1).
LAVAREDA, Antônio. (1989), "Governos, partidos e eleições segundo a opinião pública: o Brasil de 1989 comparado ao de 1964". Dados, 32 (3): 341-362.

LEWIS-BECK, Michael. (1988), Economics \& elections: the major western democracies. Ann Arbor, The University of Michigan Press.

MENDES, Manuel T. \& VENTURI, Gustavo. (1994), "Eleição presidencial: o Plano Real na sucessão de Itamar Franco". Opinião Pública, II (2).

MENEGUELLO, Raquel. (1995), "Electoral behavior in Brazil: the 1994 presidential election". International Social Science Journal, 146.

MILLER, Arthur et al. (1986), "Schematic assessments of presidential candidates". American Political Science Review, 80.

MUSZYNSKI, Judith \& MENDES, Manuel T. (1990), "Democratização e opinião pública no Brasil", in: B. Lamounier (org.), De Geisel a Collor: o balanço da transição, São Paulo, Sumaré/Idesp.

POPKIN, Samuel L. (1994), The reasoning voter: comunication and persuasion in presidential campaigns. 2 ed. Chicago, The University of Chicago Press.

RAHN, Wendy et al. (1990), "A social-cognitive model of candidate appraisal", in: J. Ferejohn e J. Kuklinski (eds.), Information and democratic processes, Illinois, University of Illinois Press.

REIS, Fábio W. \& CASTRO, Mônica M. M. (1992), "Regiões, classe e ideologia no processo eleitoral brasileiro". Lua Nova, 26: 81-131.

RENNÓ, Lúcio. (2001), "A estrutura das crenças de massa e seu impacto na decisão de voto". BIB - Revista Brasileira de Informação Bibliográfica em Ciências Sociais, 51: 85-103.

SILVEIRA, Flávio. (1996), O novo eleitor não-racional. Tese de doutorado, São Paulo, Universidade de São Paulo, FFLCH (mimeo.). 
SINGER, André. (1990), "Collor na periferia: a volta por cima do populismo?", in B. Lamounier (org.), De Geisel a Collor: o balanço da transição, São Paulo, Sumaré/Idesp.

. (1993), Ideologia e voto no segundo turno da eleição presidencial de 1989. Dissertação de mestrado, São Paulo, Universidade de São Paulo, FFLCH (mimeo.).

. (2000), Esquerda e direita no eleitorado brasileiro. São Paulo, Edusp.

WATTENBERG, Martin. (1991), The rise of candidate-centered politics. Cambridge, Harvard University Press.

(1998), The decline of American political parties (1952-1996). Cambridge, Harvard University Press.

WEISBERG, Herbert \& GREENE, Steven. (2003), "The political psychology of party identification", in Michael MacKuen e George Rabinowitz (eds.), Electoral democracy, Ann Arbor, The University of Michigan Press. 


\section{A ELEIÇÃO PRESIDENCIAL DE 2002: A DECISÃO DO VOTO NA REGIÃO DA GRAN- DE SÃo PAULO}

Yan de Souza Carreirão e Pedro Alberto Barbetta

\section{Palavras-chave}

Política brasileira; Eleições presidenciais; Comportamento eleitoral; Avaliação de desempenho governamental; Preferência partidária.

Este trabalho analisa o comportamento dos eleitores da região da Grande São Paulo, na eleição presidencial de 2002, a partir dos dados de um survey acadêmico. Por meio da análise de regressão logística, foram testadas, em um modelo para cada um dos candidatos, as influências de variáveis demográficas, socioeconômicas e atitudinais dos eleitores. A variável "sentimentos partidários", operacionalizada aqui de forma diferente da que tradicionalmente tem sido utilizada na literatura nacional (preferência partidária), mostrou-se a mais relevante nos modelos relativos ao voto em Lula e José Serra. Em vista disso, este estudo propõe um debate a respeito da forma como deve ser tratada a influência dos "sentimentos partidários" dos eleitores em sua decisão de voto.

\section{L'ÉLECTION PRÉSIDENTIELLE DE 2002: LA DÉCISION DE VOTE DANS LA RÉGION MÉ- TROPOLITAINE DE SÃO PAULO}

Yan de Souza Carreirão et Pedro Alberto Barbetta

\section{Mots-clés}

Politique brésilienne; Élections présidentielles; Comportement électoral; Évaluation de la performance gouvernementale; Préférence politique.

Le travail étudie, à partir des données d'une enquête scolaire, le comportement des électeurs de la région métropolitaine de São Paulo lors de l'élection présidentielle de 2002. Par l'analyse de la régression logistique, sont examinées, suivant un modèle spécifique pour chaque candidat, les influences des variables démographiques, socio-économiques et comportementales des électeurs. Cette dernière variable, présentée dans ce cas de façon différente de celle traditionnellement employée dans la littérature nationale (préférence politique), s'est montrée plus remarquable dans les modèles relatifs au vote en Lula et José Serra. Ce travail considère, ainsi, une discussion à propos de la façon par laquelle doit être traitée l'influence des "sentiments partisans" des électeurs dans leur décision de vote.

\section{THE PRESIDENTIAL ELECTION OF 2002: VOTING DECISION IN THE METRO AREA OF SÃO PAULO}

\author{
Yan de Souza Carreirão and \\ Pedro Alberto Barbetta
}

\section{Keywords}

Brazilian politics; Presidential elections; Electoral behavior; Governmental performance evaluation; Party preference.

This paper analyses the behavior of voters in the metro area Sao Paulo during the presidential election of 2002, based on data from an academic survey. With the use of logistic regression analysis, the influences of demographic, social, economical, and attitudinal variables relative to the voters were tested in a model for each of the candidates. The last variable, expressed here in a different way compared to the one that has been used in the national literature (party preference), seems to be the most relevant in the voting models of Lula and José Serra. Therefore, this paper proposes a debate about the way the influence of "party feelings" of voters in their voting decision must be treated. 